\title{
IDENTIDADE E DIFERENÇA: IMPERTINÊNCIAS
}

Tomaz Tadeu da SiLVA*

RESUMO: A questão da identidade e da diferença está no centro de boa parte das discussões educacionais atuais. Nessa discussão, a diferença acaba, em geral, reduzida à identidade. Nesta pequena coleção de afirmaçōes, tento, inspirado sobretudo na filosofia da diferença de Gilles Deleuze, desequilibrar o jogo em favor da diferença.

Palavras-chave: Diferença. Semelhança. Identidade. Representação.

\section{IDENTITY AND DIFFERENCE: IMPROPRIETIES}

ABSTRACT: The question of identity and difference is the center of the current educational debate where, usually, difference is reduced to identity. In this small collection of assertions, I try, inspired mostly by Gilles Deleuze's philosophy of difference, to shift the balance to the side of difference.

Key words: Difference. Likeness. Identity. Representation.

* Professor do Programa de Pós-Graduação em Educação, da Faculdade de Educação da Universidade Federal do Rio Grande do Sul (UFRGS). 
1. A diferença não tem nada a ver com o diferente. A redução da diferença ao diferente equivale a uma redução da diferença à identidade.

2. A multiplicidade não tem nada a ver com a variedade ou a diversidade. A multiplicidade é a capacidade que a diferença tem de (se) multiplicar.

3. Não é verdade que só pode diferir aquilo que é semelhante. É justamente o contrário: só é semelhante aquilo que difere.

4. A identidade é predicativa, propositiva: $x$ é isso. A diferença é experimental: o que fazer com $x$.

5. A identidade é da ordem da representação e da recognição: $\mathrm{x}$ representa $\mathrm{y}, \mathrm{x}$ é $\mathrm{y}$. A diferença é da ordem da proliferação; ela repete, ela replica: $\mathrm{x} e$ y $e$ z...

6. A diferença não é uma relação entre o um e o outro. Ela é simplesmente um devir-outro.

7. A questão não consiste em reconhecer a multiplicidade, mas em ligar-se com ela, em fazer conexóes, composiçóes com ela.

8. A diferença é mais da ordem da anomalia que da anormalidade: mais do que um desvio da norma, a diferença é um movimento sem lei.

9. Quando falamos de diferença, não estamos perguntando sobre uma relação entre $\mathrm{x}$ e $\mathrm{y}$, mas, antes, sobre como $\mathrm{x}$ devém outra coisa.

10. A diferença não pede tolerância, respeito ou boa-vontade. A diferença, desrespeitosamente, simplesmente difere.

11. A identidade tem negócios com o artigo definido: o, a. A diferença, em troca, está amasiada com o artigo indefinido: um, uma.

12. A diferença não tem a ver com a diferença entre x e y, mas com o que se passa entre $\mathrm{x}$ e $\mathrm{y}$.

13. A identidade joga pelas pontas; a diferença, pelo meio.

14. A identidade é. A diferença devém.

Recebido e aprovado em junho de 2002. 